\title{
Walter Bacci: Um diálogo entre a artista plástico e o cenógrafo
}

Danielle Menezes de Brito Semple

UNESP /Instituto de Artes; mestranda

Artes/ Estética e poéticas cênicas; orientador: Wagner Francisco Araujo Cintra

Artista plástica, graduada no ano de 2010 em licenciatura em Educação Artística com habilitação plena pela Universidade Cruzeiro do Sul/SP, possui experiência de dez anos em fotografia e pesquisa a obra do artista plástico Walter Bacci desde 2007.

\section{Resumo}

O presente projeto de pesquisa tem como objetivo estudar o artista plástico Walter Bacci, dedicado à pintura de tecido e um dos primeiros no Brasil a trabalhar com a técnica denominada silk screen. Bacci também se aproximou do teatro, como cenógrafo e figurinista de algumas das mais importantes montagens nacionais, como “Gota D'Água" de 1975. E é justamente focada neste encontro que desenvolverei a pesquisa: o diálogo que ele criou entre as duas artes, a plástica e a cênica, e como seus processos e procedimentos criativos e elementos estilísticos reverberaram por toda a sua produção artística. Apresentar a contribuição de Walter Bacci para a cenografia brasileira é o que motiva uma pesquisa aprofundada sobre a obra desse relevante artista brasileiro.

Palavras-chave: cenário, composição visual, teatro brasileiro

\section{Abstract}

\section{Walter Bacci: A dialogue between the painter and the stage designer}

This work aims at studying the artist Walter Bacci, who was committed to painting on canvas and one of the pioneers of the technique silk-screen in Brazil. During some point of his career Walter Bacci approached theater and worked as a stage and costume designer in some of the most important Brazilian theater plays, being "Gota D'Água" (1975) the most relevant of all. The dialogue between the painter and the theater designer is the very focus of this research: how his creative process and stylist elements echoed throughout his theatrical production. Presenting the contribution of Walter Bacci to the development of Brazilian stage designing is what motivates a more comprehensive research on Walter Bacci's work.

Keywords: Brazilian theater; stage design; visual composition

\section{Resumen \\ Walter Bacci: Un diálogo entre el artista plástico y el escenógrafo}

El presente proyecto de investigación tiene como objetivo estudiar al artista plástico Walter Bacci, dedicado a la pintura en tejido y uno de los primeros en Brasil en trabajar con la técnica denominada silk screen. Bacci también se aproximó al teatro, como escenógrafo y diseñador de vestuario de algunos de los más importantes montajes nacionales, como "Gota D’Água” en 1975. Y es justamente centrada en este encuentro que desenvolveré la investigación: el diálogo que él creo entre dos artes, el plástico y el escénico, y como sus procesos y procedimientos creativos y elementos estilísticos 
reverberan por toda su producción artística. Presentar la contribución de Walter Bacci a la escenografía brasileña es lo que motiva una investigación profunda sobre la obra de ese relevante artista brasileño.

Palabras clave: composición visual, escenario, teatro brasileño

\section{WALTER BACCI: UM DIÁLOGO ENTRE O ARTISTA PLÁSTICO E O CENÓGRAFO}

Este projeto de pesquisa tem por objetivo estabelecer um diálogo entre a linguagem visual nas artes plásticas e a cenografia teatral do artista Walter Bacci, analisando poeticamente ${ }^{1}$ a construção de sua composição cênica teatral entre os anos de 1962 a 1979 e paralelamente a isso a sua produção como artista plástico e como essa dualidade influenciava ambas suas produções artísticas.

Nascido em Ibirá (SP) em 1931, criado na cidade de Niterói, Walter estudou na Escola Nacional de Belas Artes do Rio de Janeiro. Trabalhou em seu atelier no Catete, no centro da cidade do Rio, onde recebia a visita de atores, atrizes, diretores e socialites da época. Provavelmente sendo o local onde criou e desenvolveu dezenas de figurinos e cenários, como o caso de "Se correr o bicho pega, se ficar o bicho come" em 1966, “Casa de bonecas” em 1971 e “Gota D’Água” (vide fig. 1) em 1975.

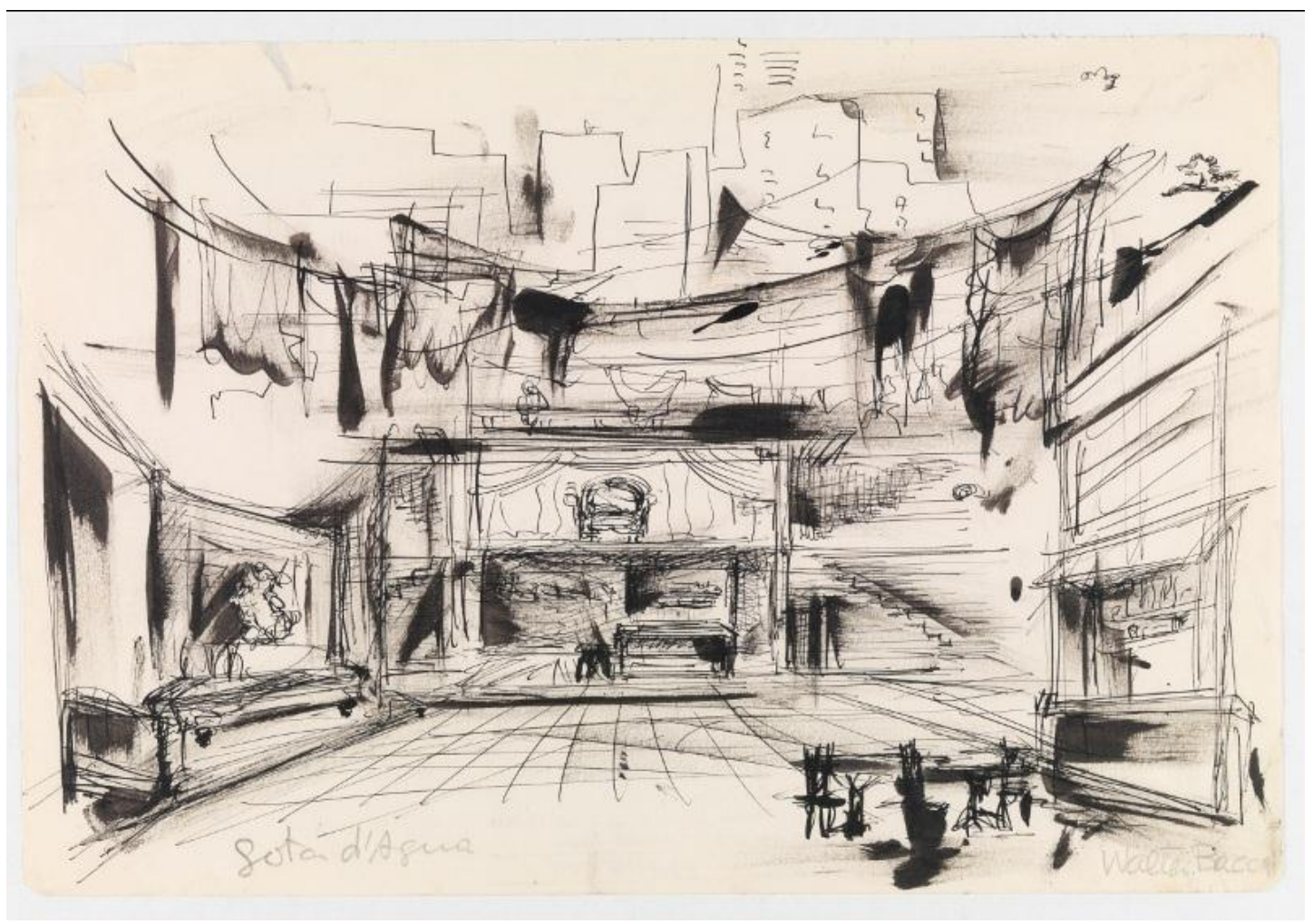

Fig. 01 - Croqui da cenografia da peça Gota d'água, s/d, número 7 - Acervo CEDOC Funarte RJ 
Bacci não se preocupava com a documentação de seu trabalho o que torna a realização desta pesquisa um grande desafio. Tal displicência poderia ser, na verdade, um reflexo de seu temperamento reservado, fato relatado pelos seus familiares, como Érica Bacci Nahon, sobrinha do artista. Nas casas dos familiares comecei a perceber que havia muitos panneaux $x^{2}$ de Walter espalhados pelos cômodos, tanto nas casas dos familiares do Rio de Janeiro quanto em São Paulo. Eram almofadas, cortinas, descansos de pratos, toalhas de mesa, camisetas, camisas, quadros pequenos e grandes. O que depois vim, a saber, é que tudo aquilo fazia parte de seus testes, os seus experimentos com o silk screen ${ }^{3}$.

Com o meu ingresso na universidade surge a vontade de trazer à luz o trabalho de Bacci, que durante décadas ficou esquecido, assim como seus desenhos nos arquivos do CEDOC-Funarte/RJ ${ }^{4}$. No desenvolvimento da minha monografia ${ }^{5}$ realizei um mapeamento a procura de suas obras, sua produção artística, para que fosse possível saber o que efetivamente ainda existia, onde estavam as suas pinturas, seus desenhos, a obra do artista Walter Bacci. E naquela pesquisa consta uma grande parte desse mapeamento da localização de suas obras. Contudo a monografia suscitou uma série de outros questionamentos, estando entre eles: qual seria a importância de um artista plástico em uma criação cênica? Qual seria o interesse de Bacci por essas peças teatrais? Estaria o artista tentando demonstrar sua posição política através do figurino/cenário e a escolha de em quais peças ele trabalharia, já que o Brasil passava por um momento político muito complexo, no que tange a liberdade de expressão? E porque essa produção findou? Encontrar os croquis da peça teatral "Gota D’Água” e descobrir que Bacci esteve envolvido em diversos e importantes movimentos artísticos brasileiros como o Concretismo ${ }^{6}$ e Neoconcretismo ${ }^{7}$ no Rio de Janeiro, o Grupo Frente ${ }^{8}$, o Opinião $65^{9}$ e expondo na Bienal de Arte de São Paulo em 1963 estimulou-me a dar prosseguimento a pesquisa, levando-me ao desenvolvimento da minha atual dissertação de mestrado na linha de pesquisa Estética e poéticas cênicas.

Todas essas informações encontradas caminharam para um dialogo entre as duas expressões artísticas de Bacci, transitando entre as artes plásticas (silk screen e telas), vestimentas (camisas e camisetas) e a cenografia e figurino teatral, sendo que seria possível afirmar que as fronteiras entre essas linguagens eram frequentemente enfraquecidas ou simplesmente ignoradas, já que Bacci usava em suas criações cênicas 
a mesma forma de pintar que usava em seus quadros. Sobre essa maneira de criar para o teatro Gianni Ratto afirmou que Bacci "transforma seu instrumento em obra de arte.”.

Justifica-se esta pesquisa pela necessidade de compreender essa relação e esse momento como um marco na trajetória artística de Bacci, e é fundamental a discussão da contribuição de Bacci tanto para o teatro quanto para as artes plásticas. Já foi observada a discussão sobre a importância da cenografia e a influência do artista plástico no universo do teatro. Jean-Pierre Ryngaert (1998) em Ler o teatro contemporâneo:

À cenografia tem o mesmo status que todas as profissões ligadas ao teatro. Não imagino uma encenação "autônoma". O teatro é, em si mesmo, um bastardo, no interior do qual se combinam diversas disciplinas. É isso que torna sua força insubstituível, e talvez seja nisso que ele é um "reflexo" da sociedade, mesmo em suas piores coisas. (RYNGAERT, 1998: 67)

O pensamento de Ryngaert encontra um ponto de contato com a obra de Bacci e de um outro artista que me servirá de referência sobre essas aproximações das artes. Será o caso do arquiteto, engenheiro, cenógrafo, teatrólogo, pintor, desenhista, escritor, filósofo, performer, e músico Flávio de Carvalho. A experiência relatada no livro Flávio de Carvalho: o artista total de Rui Moreira Leite (2008) contribui para a compreensão dos objetivos desta pesquisa. O autor descreve Flávio como um ser multifacetado, capaz de circular entre diversas áreas das artes. Um exemplo é a peça teatral "Bailado do Deus morto", na qual Flávio escreve o texto, cria a cenografia e outros elementos da linguagem cênica.

A pesquisa pretende partir de autores, Gianni Ratto, Jean Jacques Roubine, e Daisy Peccinini, Jean-Pierre Ryngaert e Cyro Del Nero que se debruçaram sobre o tema, artistas plásticos e suas contribuições ao teatro, além do embasamento teórico acerca da produção artística brasileira, musical, teatral e plástica, e abordando a historiografia das artes, que estabelece relações entre o indivíduo e o objeto. Também será necessária a formulação e a realização de uma pesquisa biográfica com familiares que vivenciaram o cotidiano de Walter Bacci e com alguns autores, produtores, atores e atrizes como Bibi Ferreira, Chico Buarque, Roberto Bonfim, Max Haus, Agildo Ribeiro, Hugo Carvana entre outros.

Desta forma, a estratégia de investigação para este projeto se caracterizará pela sistematização, análise e reflexão da construção histórica-plástica-teatral brasileira e da produção de Walter Bacci. As análises de alguns croquis de peças das quais Bacci realizou o cenário e figurinos, como a peça “Gota D’água”, serão feitas com o apoio da 
metodologia usada no livro Sintaxe da Linguagem Visual escrito por Donis A. Dondis (2007). Devido à autora analisar imagens através da comunicação visual, falando de métodos de composição e da estrutura do modo de ver (cor, forma, espaço, linhas, etc.), julgo ser esta abordagem adequada para o a pesquisa que desenvolverei.

Este projeto justifica-se pela relevância, e de até o presente momento, pela ausência de pesquisas ou publicações acadêmicas específicas sobre o artista plástico Walter Bacci, o que limita os estudos sobre a análise de sua produção. E os resultados dessa pesquisa poderão ser aplicados em posteriores consultas a área das artes cênicas, especialmente os relacionados à construção da linguagem visual pelo viés das artes plásticas e por um conhecimento mais aprofundado do figurino e da cenografia de uma geração que foi reprimida em suas expressões artísticas. O resgate da obra plástica de Walter Bacci virá a ser mais um elemento que ajude a compor a pesquisa sobre este recém-encerrado capítulo da história artística e cultural brasileira.

\section{Referências Bibliográficas}

BUARQUE, Chico; PONTES, Paulo. Gota D'água. 16ª ed. Rio de Janeiro: Civilização Brasileira, 1986.

DONDIS, Donis A. Sintaxe da linguagem visual. $2^{\mathrm{a}}$ ed. São Paulo: Martins Fontes, 1997.

HERMETO, Miriam. 'Olha a Gota que falta': um evento no campo artístico-intelectual brasileiro (1975-1980). Tese/Doutorado. Belo Horizonte: UFMG, 2010.

LEITE, Rui M. Flávio de Carvalho: o artista total. São Paulo: Senac São Paulo, 2008.

NERO, Cyro D. Máquina para os deuses: anotações de um cenógrafo e o discurso da cenografia. São Paulo: Senac São Paulo; São Paulo: SESC SP, 2009.

NOVAIS, Adauto. Anos 70: teatro. Rio de Janeiro: Europa, 1979.

ROUBINE, Jean J. A linguagem da encenação teatral. Rio Janeiro: Jorge Zahar, 1998.

RYNGAERT, Jean P. Ler o teatro contemporâneo. São Paulo: Martins Fontes, 1998.

SALLES, Cecília A. Gesto inacabado: processo de criação artística. $4{ }^{\text {a }}$ ed. São Paulo: FAPESP, 2004.

\footnotetext{
${ }^{1}$ 1. Poeticamente, de pensamento poético, de criação, ação, confecção, fabricação. Poiêsis.

2. 'Produção poética' traduz poiêsis, que traduziríamos mais imediatamente como 'poesia' (Dupont-Roc e Lallot), ou como 'poema' (Eudoro de Sousa, Bruna, Bywater), ou ainda como 'composição poética' (Hardy,Halliwell). (...) A opção por 'produção poética' explica-se principalmente por uma questão de fundo lexical: poiêsis é o substantivo grego derivado do verbo poieô (fazer, produzir) por meio do sufixo -sis, que corresponde ao português -ção, e indica
} 
o ato de realizar a idéia expressa pela raiz verbal: de 'produzir' vem 'produ-ção'. Acrescente-se a isso o fato de que a frase é construída pela perífrase verbal mellô+infinitivo futuro, que indica um ato a ser realizado, ou que se pretende que seja realizado. Tudo parece indicar que estamos no âmbito daquilo que está para ser feito, não no âmbito da coisa realizada. Mas a questão é de pormenor, se notarmos que a produção poética exitosa se identifica ao poema exitoso. E mesmo a Poética, em outros trechos, parece oscilar entre considerar poiêsis como produção poética ou como o produto final. (GAZONI, 2006:31)

${ }^{2}$ Informação obtida com a família Bacci, era um termo usado por Walter Bacci para designar suas pinturas em tecido quando ainda não tinham um destino específico. Ex: telas, almofadas, roupas e acessórios de moda.

${ }^{3}$ Silk screen ou serigrafia é um processo de impressão no qual a tinta é vazada - pela pressão de um rodo ou puxador - através de uma tela ou tecido preparado.

${ }^{4}$ Centro de documentação da Fundação Nacional das Artes localizado na cidade do Rio de Janeiro.

${ }^{5}$ SEMPLE, D. Cenários de Walter Bacci, a construção plástica da peça Gota D'água. 2010. 62fls. Monografia Universidade Cruzeiro do Sul, São Paulo.

${ }^{6}$ Movimento artístico que ocorreu entre 1950-1962. Elaboração artística em busca da forma precisa, ênfase na racionalidade, no raciocínio e na ciência. Uso de figuras abstratas nas artes plásticas, união entra a forma e o conteúdo na obra de arte.

${ }^{7}$ Movimento artístico surgido no final dos anos de 1950, como reação ao concretismo ortodoxo. Procuravam novos caminhos dizendo que a arte não é um mero objeto: tem sensibilidade, expressividade, subjetividade, indo muito além do mero geometrismo puro.

${ }^{8}$ Sob a liderança do artista carioca Ivan Serpa e de seus alunos ou ex-alunos do curso no Museu de Arte Moderna do Rio de Janeiro (MAM/RJ). O grupo não se caracteriza por uma posição estilística única, sendo o elo de união entre seus integrantes a rejeição à pintura modernista brasileira de caráter figurativo e nacionalista. Fonte: Enciclopédia Itaú Cultural

${ }^{9}$ A coletiva Opinião 65 inspirava-se no entusiasmo geral que o show organizado pelo Teatro Arena do Rio de Janeiro despertara: justamente por ser a primeira manifestação cultural organizada após e contra o golpe militar de 1964. Fonte: MAC USP. 